\title{
Moral Hazard, Social Well-being and Tropical Deforestation
}

\author{
Etienne Bienvenu Akono \\ Faculty of Economics and Applied Management \\ University of Douala, Cameroon
}

Tel: 237-7627-7925/237-9849-1225

E-mail: akonosong@yahoo.fr

Received: June 6, 2013 Accepted: July 9, 2013 Published: October 28, 2013

doi:10.5296/jee.v4i2.3820ＵRL: http://dx.doi.org/10.5296/jee.v4i2.3820

\begin{abstract}
The aim of this paper is to explore the impact of tropical deforestation due to logging activities on social well-being when there is moral hazard in the logging industry. I set up a multiperiod principal-agent model. I show that when the government cannot observe the deforestation rate realized by the logging firm, an increase in tropical deforestation decreases social well-being.
\end{abstract}

Keywords: Moral hazard, Social well-being, Tropical deforestation 


\section{Introduction}

The purpose of this article is to analyze the impact of tropical deforestation due to logging industry on social well-being when the government cannot observe the deforestation rate realized by logging firms. I set up a principal-agent framework by extending Lambert's (1983) multiperiod situations agency model which examines the role of long term contracts in controlling moral hazard problems. I show that when the government cannot observe the deforestation realized by the logging company, an increase in deforestation due to logging industry decreases social well-being.

These recent years, logging activities have become one of the major causes of deforestation in Congo Basin. In Cameroon for example, the rapid expansion of the logging sector in Cameroon had led to a $400 \%$ increase in the deforestation rate (Dudley, Jeanrenaud \& Sullivan, 1995). This great increase of deforestation stem from the fact that logging industry has become a mainstay of the economy. Despite the importance of that industry in the economy, the government is losing revenues due to wasteful deforestation because wastage is high, cutting cycles are unfeasibly short, and many of the taxes are unpaid or under evaluated. Hidden actions or wrong declarations of logging firms about the volume and the origin of the logs, on which government generally refers to levy the taxes, might favor this situation. In Cameroon for example, the official statistics for 1991/1992 classified $50 \%$ of the registered timber production as 'intermediate', meaning that this volume was wasted (Glastra, 1999). Based on the data from Cameroun-Est, the undeclared timber volume in 1992/1993 was close to one-third of the production (Cerruti \& Tacconi, 2006). The unobserved actions of logging firms reduce then government's revenues and consequently affect negatively the social wellbeing.

Much of the literature examining natural resource exploitation in the presence of informational problems has focused its attention on exhaustible resources. In a two-period framework, considering the case where companies have precontractual private information about the size of the reserves in the petroleum sector, Osmundsen (1998) analyzes how the information problem can be alleviated by managed extraction policies. He shows that in that context, the second- best optimal extraction path can be obtained by natural resource taxation license fees and royalties. Hung, Poudou and Thomas (2006) study the optimal resource extraction in the presence of adverse selection on the firm's efficiency, full commitment and perfect efficiency correlation over the periods where production is the depletion of a non renewable resource. They show that asymmetric information postpones the exhaustion date and therefore the contract duration. Different from that literature, I focus on the exploitation of renewable natural resource, and precisely on tropical deforestation, when there is moral hazard in the logging industry by using an agency model. In addition, my paper is not interested on studying the optimal deforestation path or optimal harvest contract in controlling moral hazard but analyzes the effect of deforestation on social well-being when there is such informational problem between the principal (government) and the agent ( logging firms). 


\section{The Model}

To examine the impact of deforestation on the social well-being when there is moral hazard in the logging industry, let suppose that the government, the principal, grants a logging concession to a logging firm, the agent, through a competitive acquisition. Let denote government and logger respectively by $\mathrm{G}$ and $\mathrm{F}$. Let suppose that the action of $\mathrm{F}$ consists to deforest. In order to maximize its profit in period $t, \mathrm{~F}$ chooses to realize a deforestation rate $d_{t} \in(0,1)$. $d_{t}$ generates a gross timber volume $Q_{t}$ each period $t$. We assume that $\Omega_{t}$, the set of possible $Q_{t}$, is a finite set. Let suppose that there is uncertainty in the timber harvest process. Uncertainty arises because $Q_{t}$ changes with weather conditions specifically the rain season as is the case in most African countries exporting timber products. ${ }^{1}$ To take this uncertainty to account, let denote $p_{t}\left(Q_{t} / d_{t}\right)$ the probability for $Q_{t}$ occurring given that $d_{t}$ is realized by F. We assume that the state variables $\left(Q_{t}\right)$ are independently distributed over time. Let suppose that the probability $p_{t}\left(Q_{t} / d_{t}\right)$ is differentiable with respect to $Q_{t}$ where its derivative is denoted $p_{t}^{\prime}\left(Q_{t} / d_{t}\right)$.

To simplify, I suppose that $p_{t}\left(Q_{t} / d_{t}\right)=e^{-Q_{t}}$. It is straightforward to see that $p_{t}^{\prime}\left(Q_{t} / d_{t}\right) \prec 0$, which implies that logging firm tends to produce less timber when it increases its logging efforts. This assumption might seem an unreasonable property of the distribution of the gross timber volume, however logging firm could produce less timber volume even if it increases its deforestation rate when using clear-cutting method to harvest the timber.

I assume that $\mathrm{G}$ chooses only to impose stumpage taxes to the logging firm. G's strategy is to collect those taxes paid by the logger to harvest the forest at each period $t$. Let denote $\tau_{t}\left(Q_{1}, Q_{2}, \ldots, Q_{t}\right) \in[\underline{\tau}, \bar{\tau}] \in \mathfrak{R}_{+}$, the stumpage taxes paid by the logging firm in period $t$ when the gross timber volume in periods one through $t$ is $\left(Q_{1}, Q_{2}, \ldots, Q_{t}\right)$. Let then define a strategy for $\mathrm{G}$ in period $t$ as a sequence of functions:

$$
\tau=\left\{\tau_{1}\left(Q_{1}\right), \tau_{2}\left(Q_{1}, Q_{2}\right), \ldots, \tau_{t}\left(Q_{1}, Q_{2}, \ldots, Q_{t}\right)\right\}
$$

The logging firm's strategy is to choose the gross timber volume in each period $t$. I assume

\footnotetext{
${ }^{1}$ Since the road infrastructures giving access to the harvested forests are very poor quality, during the rain season it is very difficult for the logging firm to transport the timber from the unit process installed in the forest to the port.
} 
that F's choice on $Q_{t}$ depends on the deforestation rate realized in the prior period. This assumption means that $Q_{t}$ is function of $\left(d_{1}, d_{2}, \ldots, d_{t-1}\right)$. A strategy for $\mathrm{F}$ in period $t$ can therefore be represented as:

$$
Q=\left\{Q_{1}, Q_{2}\left(d_{1}\right), \ldots, Q_{t}\left(d_{1}, d_{2}, \ldots, d_{t-1}\right)\right\}
$$

As we can see from relations (1) and (2), each time the logging concession is renewed, each player's strategy depends on what it has observed up to that point in time, i.e. its information history. Since relation (1) does not depend on the current deforestation rate, i.e. $d_{t}$, this reflects the fact that there is a moral hazard between the government and the logging firm during the logging process. $\mathrm{G}$ cannot learn or observe the deforestation rate realized by $\mathrm{F}$ in period ${ }^{t}$ during the logging harvest process 2 .

Let suppose that $\mathrm{F}$ possesses a utility function which is additively separable by periods. G's and F's utility functions are respectively $\sum_{t=1}^{T} u_{t}\left[\tau_{t}\right]$ and $\sum_{t=1}^{T}\left\{h_{t}\left(Q_{t}\right)-g_{t}\left(\tau_{t}\right)\right\}$. These utility functions vary with time. Different from the literature on moral hazard (Holmstrom, 1979; Lambert, 1983) which considers the agent's action as an effort with direct disutility because of strenuousness, we consider the action of logging firm i.e. gross timber production as pleasant for its utility because to make money the logger has to harvest. $h_{t}\left(Q_{t}\right)$ is then defined as returns function and $g_{t}\left(\tau_{t}\right)$ is the logging tax payment function. Let assume that the government's utility function which depends solely on $\tau_{t}$ represents the social well-being. As assumed above let F's utility be separable into gross timber volume component and stumpage taxes component: $S_{t}(\tau, Q)=h_{t}(Q)-g_{t}(\tau)$.When the strategy pair is $(\tau, Q)$, let denote $U(\tau, Q)$ and $V(\tau, Q)$ the expected utility to, respectively, $\mathrm{G}$ and $\mathrm{F}$ over T-period. When the strategy pair $(\tau, Q)$ is used let define $\mathrm{G}$ and $\mathrm{F}$ expected utilities respectively by:

$$
U(\tau, Q)=E\left[\sum_{t=1}^{T} u_{t}\left[\tau_{t}\left(Q_{1}, Q_{2}, \ldots, Q_{t}\right)\right]\right]
$$

\footnotetext{
${ }^{2}$ In Cameroon there is a such moral hazard phenomenon in the logging industry since the government generally relies on the information provided by logging companies to set and collect stumpage fees which depend on the cutting area i.e. deforestation rate.
} 
And

$V(\tau, Q)=E\left[\sum_{t=1}^{T} S_{t}\left[\tau_{t}\left(Q_{1}, Q_{2}, \ldots, Q_{t}\right), Q_{t}\left(d_{1}, d_{2}, \ldots, d_{T-1}\right)\right]\right]$

I assume that $u_{t}\left(\tau_{t}\right)$ is strictly increasing and concave. This assumption ensures that, as usual, the government likes money and it is risk averse or risk neutral. I assume that the agent prefers to pay less stumpage taxes to more i.e. $g_{t}^{\prime}\left(\tau_{t}\right) \prec 0$ and that $g_{t}^{\prime \prime}\left(\tau_{t}\right) \prec 0$. Since the problem of moral hazard can be avoided when the agent is risk-neutral (Harris \& Raviv, 1976), I assume that $h_{Q_{t} Q_{t}}\left(Q_{t}\right) \prec 0$, meaning that $\mathrm{F}$ is risk averse. $\mathrm{G}$ can be risk neutral or risk averse to deforestation. This behavior does not influence the results and it is not important for our analysis. I further assume that $\mathrm{F}$ prefers more gross timber volume to less (i.e. $\left.h_{Q_{t}}\left(Q_{t}\right) \succ 0\right)$. I assume that the concession contract signed by both parties is optimal even if in reality it is non-enforceable since the weak capacity of the government makes it difficult to monitor the actions (i.e. gross timber volume production) of the logging company ${ }^{3}$.

Assuming that $G$ and $F$ are rational, the government's objective consists to determine optimally $\tau_{t}$ by solving the Pareto-optimization program:

$\max _{\tau_{t}} U(\tau, Q)$

Subject to $V(\tau, Q) \geq V$

$Q \in \arg \max _{\hat{Q}} V(\tau, \hat{Q})$

Where the notation" arg max"denotes the set of arguments that maximize the objective that follows. Constraint (5) requires the logging process to guarantee $\mathrm{F}$ a minimum expected utility $V^{*}$ over the T-period horizon viewed from the beginning of period one. $V^{*}$ could represent the utility that the logging firm would achieve over the T-period when it obtains zero profit. Constraint (6) reflects the restriction that $\mathrm{G}$ cannot observe the current deforestation rate in each period $t$, since the current gross timber volume depends on the prior deforestation rate. More precisely this constraint represents the moral hazard

\footnotetext{
${ }^{3}$ As is the case in most of African timber exports countries such as Cameroon.
} 
phenomenon. Constraint (6) requires the logging company's strategy to be the best response, or incentive compatible, to the government's forest tax policy so that the logging firm can take advantage of the private information it possesses.

\section{Results and Discussions}

Let establish the Kuhn-Tucker necessary conditions by solving the above Pareto optimization program. These conditions are useful to link social well-being and deforestation when the logger enjoys an informational advantage than the government. I explore in details a two period situation and then propose a generalization for the T-period $(t \succ 2)$ framework.

There is a classic literature on principal-agent settings which suggests a standard approach to solve the government optimization problem (Mirrlees, 1974, 1975, 1976; Holmstrom, 1979; Lambert, 1981, 1983; Rogerson, 1985). This method, the so-called first-order approach, involves weakening the constraint that the agent chooses a utility maximizing action to require instead only that the agent chooses an action at which its utility is at a stationary point (Rogerson, 1985). Formally, this means that since

$Q \in \arg \max _{\hat{Q}} V(\tau, \hat{Q})$ is actually a continuum of constraints of the form $V(\tau, Q) \geq V(\tau, \hat{Q})$ for every $\hat{Q}$, the first-order approach requires substituting the constraint $(6)$ by $V_{Q_{t}}(\tau, Q)=0$ so that a solution can be calculated using the Kuhn-Tucker Theorem. Mirrlees (1979) points out that the solutions to G's maximization problem using the constraint (6) (i.e. the unrelaxed program) or $V_{Q_{t}}(\tau, Q)=0$ (i.e. the relaxed program) will not be always the same. In particular, necessary conditions to solve the relaxed program derived by using the Kuhn-Tucker Theorem may not even be necessary conditions to solve the unrelaxed program. Mirrlees (1979), Lambert (1981) and Rogerson (1985) show that the first-order method is valid (i.e. the unrelaxed and relaxed programs give the same solutions) if the monotone likelihood ratio condition (MLRC) and the convexity of the distribution function condition (CDFC) are satisfied and $V_{Q_{t} Q_{t}}(\tau, Q) \leq 0^{4}$.

\section{${ }^{4}$ Definitions}




\section{Macrothink}

To solve the government's optimization problem, I use the first order approach. To guarantee the validity of this approach we assume that $p_{t}\left(Q_{t} / d_{t}\right)$ satisfies both MLRC and $\mathrm{CDFC}$ and that $V_{Q_{t} Q_{t}}(\tau, Q) \leq 0$.

\subsection{The Two-Period Horizon}

In the same reasoning with Lambert (1983), to simplify the logging firm's compatibility constraint (i.e. constraint (6)) in order to use the first-order approach method, let use a dynamic programming approach to determine F's optimal strategy. When the logging firm gets to the second period, it will decide optimally its gross timber volume conditional upon the information that it has at that time. Because of the separability of its utility function over time, F does not need to remember what the first period gross timber volume was when the time comes to choose its second period gross timber volume. Given its optimal second period gross timber volume, it chooses its first period timber volume to maximize its expected two period utility. The constraint (6) can therefore be expressed for each $d_{1}$ as:

$$
Q_{2}^{*}\left(d_{1}\right) \in \underset{Q_{2}}{\arg \max } E S_{2}\left[\tau_{2}\left(Q_{1}, Q_{2}\right), Q_{2}\right]
$$

And

$$
Q_{1}^{*} \arg \max _{Q_{1}} E\left\{S_{1}\left[\tau_{1}\left(Q_{1}\right), Q_{1}\right]+S_{2}\left[\tau_{2}\left(Q_{1}, Q_{2}\right), Q_{2}^{*}\left(d_{1}\right)\right]\right\}
$$

Let assume an interior solution for $Q_{1}$ and $Q_{2}\left(d_{1}\right)$ for all $d_{1}$. Using the first order approach to solve G's optimization program, F will choose its optimal gross timber volume such that to

1. The functions $p_{t}\left(Q_{t} / d_{t}\right)$ satisfy the MLRC if $d_{t}^{*} \prec d_{t}^{* *}$ implies that $\frac{p_{t}\left(Q_{t} / d_{t}^{*}\right)}{p_{t}\left(Q_{t} / d_{t}^{* *}\right)}$ is non-increasing in $Q_{t}$.

2. The functions $p_{t}\left(Q_{t} / d_{t}\right)$ satisfy the $\mathrm{CDFC}$ if $F^{\prime \prime}\left(Q_{t} / d_{t}\right)$ is non-negative for any $Q_{t} \in\left(Q_{1}, Q_{2}, \ldots, Q_{T}\right)$ and $d_{t} \in(0,1)$, where $F\left(Q_{t} / d_{t}\right)=\sum_{t=1}^{T} p_{t}\left(Q_{t} / d_{t}\right)$ is the distribution function. 
satisfy for each $d_{1}$

$$
h_{2}^{\prime}\left[Q_{2}\left(d_{1}\right)\right]-\sum g_{2}\left[\tau_{2}\left(Q_{1}, Q_{2}\right)\right] p_{2}^{\prime}\left[Q_{2} / d_{2}\left(Q_{1}\right)\right]=0
$$

And

$$
h_{1}^{\prime}\left(Q_{1}\right)-\sum\left\{g_{1}\left[\tau_{1}\left(Q_{1}\right)\right]+E S_{2}\left[\tau_{2}\left(Q_{1}, Q_{2}\right), Q_{2}\left(d_{1}\right)\right]\right\} p_{1}^{\prime}\left(Q_{1} / d_{1}\right)=0
$$

Equation (9) is analogous to the logging firm's first order condition on optimal gross timber volume in a one period model. F chooses its gross timber volume so that its effect on marginal utility of timber volume is equal to its marginal disutility of stumpage taxes. Equation (10) is similar to (9) except that F must also consider the effect that $Q_{1}$ has on $Q_{2}\left(d_{1}\right)$ and on $\tau_{2}\left(Q_{1}, Q_{2}\right)$. Let then represent F's choice of optimal gross timber volume by the above corresponding first order conditions.

To solve the G's optimization program we now replace constraints (7) and (8) respectively by constraints (9) and (10). Let use the Lagrangian formulation to represent G's problem. Let $\lambda, \quad \beta_{1}$ and $\beta_{2}\left(d_{1}\right)$ be respectively the Lagrange multipliers on (5), (9) and (10) constraints. The Lagrangian function is then defined by:

$$
\begin{aligned}
& L\left[\tau_{1}\left(Q_{1}\right), \tau_{2}\left(Q_{1}, Q_{2}\right), Q_{1}, Q_{2}\left(d_{1}\right), \lambda, \beta_{1}, \beta_{2}\left(d_{1}\right)\right] \\
& =\sum\left\{u_{1}\left[\tau_{1}\left(Q_{1}\right)\right]+\sum u_{2}\left[\tau_{2}\left(Q_{1}, Q_{2}\right)\right] p_{2}\left[Q_{2} / d_{2}\left(Q_{1}\right)\right]\right\} p_{1}\left(Q_{1} / d_{1}\right) \\
& +\lambda\left\{h_{1}\left(Q_{1}\right)+V^{*}-\sum\left\{g_{1}\left[\tau_{1}\left(Q_{1}\right)\right]+h_{2}\left[Q_{2}\left(d_{1}\right)\right]-\sum g_{2}\left[\tau_{2}\left(Q_{1}, Q_{2}\right)\right] p_{2}\left[Q_{2} / d_{2}\left(Q_{1}\right)\right]\right\} p_{1}\left(Q_{1} / d_{1}\right)\right\} \\
& +\beta_{1}\left\{h_{1}^{\prime}\left(Q_{1}\right)-\sum\left\{g_{1}\left[\tau_{1}\left(Q_{1}\right)\right]+h_{2}\left[Q_{2}\left(d_{1}\right)\right]-\sum g_{2}\left[\tau_{2}\left(Q_{1}, Q_{2}\right)\right] p_{2}\left[Q_{2} / d_{2}\left(Q_{1}\right)\right]\right\} p_{1}^{\prime}\left(Q_{1} / d_{1}\right)\right\} \\
& +\sum \beta_{2}\left(d_{1}\right)\left\{h_{2}^{\prime}\left[Q_{2}\left(d_{1}\right)\right]-\sum g_{2}\left[\tau_{2}\left(Q_{1}, Q_{2}\right)\right] p_{2}^{\prime}\left[Q_{2} / d_{2}\left(Q_{1}\right)\right]\right\}
\end{aligned}
$$

The Kuhn-Tucker necessary conditions of an interior solution of the Lagrangian function in the one period and two period horizons respectively satisfy:

$$
\frac{u_{1}^{\prime}\left[\tau_{1}\left(Q_{1}\right)\right]}{g_{1}^{\prime}\left[\tau_{1}\left(Q_{1}\right)\right]}=\lambda+\beta_{1} \frac{p_{1}^{\prime}\left(Q_{1} / d_{1}\right)}{p_{1}\left(Q_{1} / d_{1}\right)}
$$

And 


$$
\frac{u_{2}^{\prime}\left[\tau_{2}\left(Q_{1}, Q_{2}\right)\right]}{g_{2}^{\prime}\left[\tau_{2}\left(Q_{1}, Q_{2}\right)\right]}=\lambda+\beta_{1} \frac{p_{1}^{\prime}\left(Q_{1} / d_{1}\right)}{p_{1}\left(Q_{1} / d_{1}\right)}+\frac{\beta_{2}\left(d_{1}\right)}{p_{1}\left(Q_{1} / d_{1}\right)} \frac{p_{2}^{\prime}\left[Q_{2} / d_{2}\left(Q_{1}\right)\right]}{p_{2}\left[Q_{2} / d_{2}\left(Q_{1}\right)\right]}
$$

To find the optimal gross timber volume strategy, let differentiate the Lagrangian formulation with respect to $Q_{1}$ and $Q_{2}\left(d_{1}\right)$ and using $(9)$ and $(10)$ to get

$$
\begin{aligned}
& \sum\left\{u_{1}\left[\tau_{1}\left(Q_{1}\right)\right]+E u_{2}\left[\tau_{2}\left(Q_{1}, Q_{2}\right)\right]\right\} p_{1}^{\prime}\left(Q_{1} / d_{1}\right) \\
& +\beta_{1}\left\{h_{1}^{\prime \prime}\left(Q_{1}\right)-\sum\left\{g_{1}\left[\tau_{1}\left(Q_{1}\right)\right]+E S_{2}\left[\tau_{2}\left(Q_{1}, Q_{2}\right), Q_{2}\left(d_{1}\right)\right]\right\} p_{1}^{\prime \prime}\left(Q_{1} / d_{1}\right)\right\}=0 \\
& \sum u_{2}\left[\tau_{2}\left(Q_{1}, Q_{2}\right)\right] p_{2}^{\prime}\left[Q_{2} / d_{2}\left(Q_{1}\right)\right] \\
& \quad+\frac{\beta_{2}\left(d_{1}\right)}{p_{1}\left(Q_{1} / d_{1}\right)}\left\{\sum h_{2}^{\prime \prime}\left[Q_{2}\left(d_{1}\right)\right]-\sum g_{2}\left[\tau_{2}\left(Q_{1}, Q_{2}\right)\right] p_{2}^{\prime \prime}\left[Q_{2} / d_{2}\left(Q_{1}\right)\right]\right\}=0
\end{aligned}
$$

The terms multiplying $\beta_{1}$ and $\beta_{2}\left(d_{1}\right)$ are the logging firm's second order conditions on its selection of $Q_{1}$ and $Q_{2}\left(d_{1}\right)$, respectively. Since these terms are assume to be negative, it is straightforward to see that

$$
\operatorname{Sign}\left(\beta_{1}\right)=\operatorname{Sign}\left[\sum\left\{u_{1}\left[\tau_{1}\left(Q_{1}\right)\right]+E u_{2}\left[\tau_{2}\left(Q_{1}, Q_{2}\right)\right]\right\} p_{1}^{\prime}\left(Q_{1} / d_{1}\right)\right]
$$

And

$$
\operatorname{Sign}\left[\beta_{2}\left(d_{1}\right)\right]=\operatorname{Sign}\left[\sum u_{2}\left[\tau_{2}\left(Q_{1}, Q_{2}\right)\right] p_{2}^{\prime}\left[Q_{2} / d_{2}\left(Q_{1}\right)\right]\right]
$$

Let define $\lambda_{2}\left(d_{1}\right)=\lambda+\beta_{1} \frac{p_{1}^{\prime}\left(Q_{1} / d_{1}\right)}{p_{1}\left(Q_{1} / d_{1}\right)}$ and $\hat{\beta}_{2}\left(d_{1}\right)=\frac{\beta_{2}\left(d_{1}\right)}{p_{1}\left(Q_{1} / d_{1}\right)}$. The Kuhn-Tucker necessary condition in the second period is then write as

$$
\frac{u_{2}^{\prime}\left[\tau_{2}\left(Q_{1}, Q_{2}\right)\right]}{g_{2}^{\prime}\left[\tau_{2}\left(Q_{1}, Q_{2}\right)\right]}=\lambda_{2}\left(d_{1}\right)+\hat{\beta}_{2}\left(d_{1}\right) \frac{p_{2}^{\prime}\left[Q_{2} / d_{2}\left(Q_{1}\right)\right]}{p_{2}\left[Q_{2} / d_{2}\left(Q_{1}\right)\right]}
$$

Since $Q_{1}$ is chosen and $d_{1}$ is observed before the choice of $Q_{2}\left(d_{1}\right)$, the terms $\frac{p_{1}^{\prime}\left(Q_{1} / d_{1}\right)}{p_{1}\left(Q_{1} / d_{1}\right)}$ and $\hat{\beta}_{2}\left(d_{1}\right)$ are determined before the agent chooses $Q_{2}\left(d_{1}\right)$. This means that $\lambda_{2}\left(d_{1}\right)$ and $\hat{\beta}_{2}\left(d_{1}\right)$ are fixed constants at the start of the second period.

In fact, all of the second-period equations, (9),(12) and (14), are exactly the same 
equations as would be derived in a one-period agency model corresponding to the second-period utility functions of the government and the logging firm. The first-period outcome acts only as a parameter to determine which of the (constrained) Pareto efficient one-period solutions the principal and the agent will arrive at in the second period. It is therefore easy to show, by using the same proofs as in Holmstrom's one-period model and Lambert's two-period, that the Lagrange multipliers for the optimal gross timber volume of the agent's one-period and second-period horizons are both negative.

Proposition $1 \beta_{1} \prec 0$

Proposition $2 \quad \hat{\beta}_{2}\left(d_{1}\right) \prec 0$ for each $d_{1}$

The proofs of these propositions are in the Appendix.

Proposition 2 implies that $\beta_{2}\left(d_{1}\right) \prec 0$ since $p_{1}\left(Q_{1} / d_{1}\right) \succ 0$. Propositions 1 and 2 mean then that the sign of the derivatives of the government's expected utility (i.e. social wellbeing) with respect to $Q_{1}$ and $Q_{2}\left(d_{1}\right)$ are both negative. In other words, in the one period and in the two-period horizons, under MLRC and CDFC assumptions, when the government cannot observe the deforestation rate realized by the logging firm, an increase of tropical deforestation due to logging industry decreases the government's expected utility i.e. the social wellbeing.

\subsection{The T-Period Horizon}

The T-period horizon analysis is a generalization of the two period framework discussed above. Let then apply the same reasoning as the one use in the two period horizon analysis. Let denote $\lambda$ and $\beta_{t}\left(d_{t-1}\right)$ respectively the Lagrange multipliers on the constraint that the logging firm obtains at least $V^{*}$ expected utility over the T-period horizon (i.e. constraint (5)) and on the moral hazard phenomenon constraint (i.e. constraint (6)). It is straightforward to show that the Kuhn-Tucker necessary conditions to obtain an interior solution for the optimization of the government's program in a T- period scheme satisfy:

$$
\frac{u_{t}^{\prime}\left[\tau_{t}\left(Q_{t-1}, Q_{t}\right)\right]}{g_{t}^{\prime}\left[\tau_{t}\left(Q_{t-1}, Q_{t}\right)\right]}=\lambda_{t}\left(d_{t-1}\right)+\hat{\beta}_{t}\left(d_{t-1}\right) \frac{p_{t}^{\prime}\left[Q_{t} / d_{t}\left(Q_{t-1}\right)\right]}{p_{t}\left[Q_{t} / d_{t}\left(Q_{t-1}\right)\right]}
$$

Where $\lambda_{t}\left(d_{t-1}\right)=\lambda+\sum_{j=1}^{t-1} \hat{\beta}_{j}\left(d_{j-1}\right) \frac{p_{j}^{\prime}\left[Q_{j} / d_{j}\left(Q_{j-1}\right)\right]}{p_{j}\left[Q_{j} / d_{j}\left(Q_{j-1}\right)\right]}$ 
And $\quad \hat{\beta}_{t}\left(d_{t-1}\right)=\frac{\beta_{t}\left(d_{t-1}\right)}{\prod_{j=1}^{t-1} p_{j}\left[Q_{j} / d_{j}\left(Q_{j-1}\right)\right]}$.

As in the two-period framework, it is straightforward to show that in T-period, $\hat{\beta}_{t}\left(d_{t-1}\right) \prec 0$ for all $d_{t-1}$ by differentiating the Lagrangian to find the optimal gross timber volume strategy. This relation implies that $\beta_{t}\left(d_{t-1}\right) \prec 0$ for all $d_{t-1}$ since $p_{j}\left[Q_{j} / d_{j}\left(Q_{j-1}\right)\right] \succ 0$ for $j \in\{1,2, \ldots t-1\}$. The sign of the derivatives of the government's expected utility (i.e. social wellbeing) with respect to timber volume is then negative in the T-period model. In other words, in the T-period horizon, under MLRC and CDFC assumptions, when the government cannot observe the deforestation rate realized by the logging firm, an increase of tropical deforestation due to logging industry decreases the government's expected utility i.e. the social wellbeing.

\section{Conclusion}

I showed that when the government cannot observe the deforestation rate realized by the logging firm, an increase in tropical deforestation due to logging activities would decrease social well-being. To obtain this result, I set up a multiperiod agency model in which government, the principal grants a logging contract to a logging firm, the agent. To take to account the presence of moral hazard in the logging industry, we defined government's strategy as a sequence of functions not depending on the current deforestation rate realized by the logger. I used the first-order approach method to establish the Kuhn-Tucker necessary conditions by solving government's Pareto optimization program in order to establish the relation between social well-being and deforestation when the logging company enjoys informational advantage than the government.

The problems of moral hazard in particular and informational problems in general are likely to be more severe in the logging industry than in other industry in Cameroon. There are two reasons for this: weak logging concession's enforcement capacity of the government and corruption. One remedy to this problem would be to invest resource into monitoring of loggers' actions. In simple situations, complete monitoring may be possible. However, generally, logging activities are very complex and full observation of logging companies' actions is either impossible or prohibitively costly. Since the government might know the technology capacity of the logger when granting him a logging title, a conceivable remedy, to avoid or reduce moral hazard phenomenon and consequently to curb the loose of revenues seems to be the input regulation. In logging activities, the equipments used by logger are good indicators of the timber volume produced in a given estate and a given period. Imposing those equipments would be more rentable than output taxation such as stumpage tax.

This work is limited since it focuses only on moral hazard phenomena. Problems of moral hazard and adverse selection often appear simultaneously in real economic phenomena. It 
will be an exciting task to extend this work by examining simultaneously these two informational problems.

\section{References}

Cerutti, P. O., \& Tacconi, L. (2006). Forests, Illegality, and Livelihoods in Cameroon, Bogor Barat: Center for International Forestry Research.

Dudley, N., Jeanrenaud, J. P., \& Sullivan, F. (1995). Bad harvest? The Timber Trade and the Degradation of the World's Forests. London: Earthscan.

Glastra, R. (1999). Cut and Run: Illegal Logging and Timber Trade in the Tropics. Ottawa: International Development Research Centre. PMid: 10454887

Holmstrom, B. (1979). Moral Hazard and Observability. The Bell Journal of Economic, 10, 74-91. http://dx.doi.org/10.2307/3003320

Hung, N. M., Poudou, J. C., \&, Thomas, L. (2006). Optimal resource extraction contract with $\begin{array}{lllll}\text { adverse } \quad \text { selection. } & \text { Resources } & \text { 78-85. }\end{array}$ http://dx.doi.org/10.1016/j.resourpol.2006.07.001

Lambert, R. A. (1981). Managerial Incentives in Multiperiod Agency Relationships. (Unpublished Doctoral dissertation), Stanford University.

Lambert, R. A. (1983). Long-Term Contracts and Moral Hazard. The Bell Journal of Economics, 14, 441-452. http://dx.doi.org/10.2307/3003645

Mirrlees, J. (1974). Notes on Welfare Economics, Information and Uncertainty. In B. McFadden, \& Wu (Eds.), Essays on Economic Behavior under Uncertainty. Amsterdam: North-Holland.

Mirrlees, J. (1975). The Theory of Moral Hazard and Unobservable behavior-Part I, Oxford: mimeo, Nuffield College.

Mirrlees, J. (1976). The Optimal Structure of Incentives and Authority within an Organization. Bell Journal of Economics, 7, 105-131. http://dx.doi.org/10.2307/3003192

Osmundsen, P. (1998). Dynamic Taxation of Non-Renewable Natural Resources under Asymmetric Information about Reserves. The Canadian Journal of Economics, 31, 933-951. http://dx.doi.org/10.2307/136501

Rogerson, W. P. (1985). The First-Order Approach to Principal-Agent Problems. Econometrica, 53, 1357-1367. http://dx.doi.org/10.2307/1913212

\section{Appendix}

\section{Proof of proposition 1}

Let $\tau_{1}\left(Q_{1}\right)$ be a second-best government stumpage taxes for a given $\lambda$. If $\beta_{1} \geq 0$, contrary to 
our claim, then $\frac{u_{1}^{\prime}\left[\tau_{1}\left(Q_{1}\right)\right]}{g_{1}^{\prime}\left[\tau_{1}\left(Q_{1}\right)\right]}=\lambda+\beta_{1} \frac{p_{1}^{\prime}\left(Q_{1} / d_{1}\right)}{p_{1}\left(Q_{1} / d_{1}\right)} \leq \lambda=\frac{u_{1}^{\prime}\left[\tau_{1 \lambda}\left(Q_{1}\right)\right]}{g_{1}^{\prime}\left[\tau_{1 \lambda}\left(Q_{1}\right)\right]}$,

For $Q_{1} \in \square{ }_{-}=\left\{Q_{1} / p_{1}^{\prime}\left(Q_{1}\right) \prec 0\right\}$. Here, $\tau_{1 \lambda}\left(Q_{1}\right)$ is the first-best government stumpage tax corresponding to $\lambda$. Since $\frac{u_{1}^{\prime}\left[\tau_{1}\left(Q_{1}\right)\right]}{g_{1}^{\prime}\left[\tau_{1}\left(Q_{1}\right)\right]}$ is increasing in $\tau_{1}\left(Q_{1}\right)$ for fixed $Q_{1}, \tau_{1 \lambda}\left(Q_{1}\right)$ is an increasing function and from $\left(A_{1}\right), \tau_{1}\left(Q_{1}\right) \leq \tau_{1 \lambda}\left(Q_{1}\right), Q_{1} \in \square$. . This implies that

$\sum\left\{u_{1}\left[\tau_{1}\left(Q_{1}\right)\right]+E u_{2}\left[\tau_{2}\left(Q_{1}, Q_{2}\right)\right]\right\} p_{1}^{\prime}\left(Q_{1} / d_{1}\right) \leq \sum\left\{u_{1}\left[\tau_{1 \lambda}\left(Q_{1}\right)\right]+E u_{2}\left[\tau_{2 \lambda}\left(Q_{1}, Q_{2}\right)\right]\right\} p_{1}^{\prime}\left(Q_{1} / d_{1}\right) \prec 0$ Let denote this relation by $\left(A_{2}\right)$. In $\left(A_{2}\right)$, the last inequality follows from the assumption $p_{1}^{\prime}\left(Q_{1} / d_{1}\right) \prec 0$ and the fact that $\tau_{1 \lambda}\left(Q_{1}\right)$ is increasing.

The expression in braces in equation (13) is the second-order condition for the government's optimization problem and hence it is negative. (It cannot be equal to zero since then $\left(A_{2}\right)$ and (13) would be inconsistent). Combining (13) and $\left(A_{2}\right)$, this implies that $\beta_{1} \prec 0$, which contradicts our contrapositive assumption $\beta_{1} \geq 0$. We reached to a contradiction assuming $\beta_{1} \geq 0$ and we conclude that $\beta_{1} \prec 0$. Q.E.D.

\section{* Proof of proposition 2}

By using the same reasoning as in the proof of proposition $1, \hat{\beta}_{2}\left(d_{1}\right) \geq 0$ implies that

$$
\sum u_{2}\left[\tau_{2}\left(Q_{1}, Q_{2}\right)\right] p_{2}^{\prime}\left[Q_{2} / d_{2}\left(Q_{1}\right)\right] \leq \sum u_{2}\left[\tau_{2 \lambda}\left(Q_{1}, Q_{2}\right)\right] p_{2}^{\prime}\left[Q_{2} / d_{2}\left(Q_{1}\right)\right] \prec 0
$$

where the last inequality follows by the assumption $p_{2}^{\prime}\left[Q_{2} / d_{2}\left(Q_{1}\right)\right] \prec 0$ and because $\tau_{2 \lambda}\left(Q_{1}, Q_{2}\right)$ is increasing. However, by using equation (14) and $\left(A_{3}\right)$, $\sum u_{2}\left[\tau_{2}\left(Q_{1}, Q_{2}\right)\right] p_{2}^{\prime}\left[Q_{2} / d_{2}\left(Q_{1}\right)\right] \prec 0$ contradicts $\hat{\beta}_{2}\left(d_{1}\right) \geq 0$. I conclude then that $\hat{\beta}_{2}\left(d_{1}\right) \prec 0$. Q.E.D. 